\title{
MUHAMMAD IBN ‘ABD AL-WAHHÂB \\ DAN \\ GERAKAN WAHABI
}

\author{
Mansur Mangasing \\ STAIN Datokarama Palu, Jl. Diponegoro 23 Palu \\ e-mail: Mansur_mangasing@yahoo.com
}

\section{Abstract}

In the Islamic world, in the middle age, the ideas on reformation and the efforts of purification of akîdah had emerged. This was a reaction against the extant political condition and tauhid comprehension of Muslims. In Arab, a chief figure, Muhammad ibn 'Abd al-Wahhâb who possessed a great concern towards the matter of akidah purification of Muslims and Islamic reformation, emerged. The efforts of al-Wahhâb finally developed into a movement called the Wahabiyyah Movement. The main target of this movement was to purify Muslims' akîdah that had been mixed with heretics.

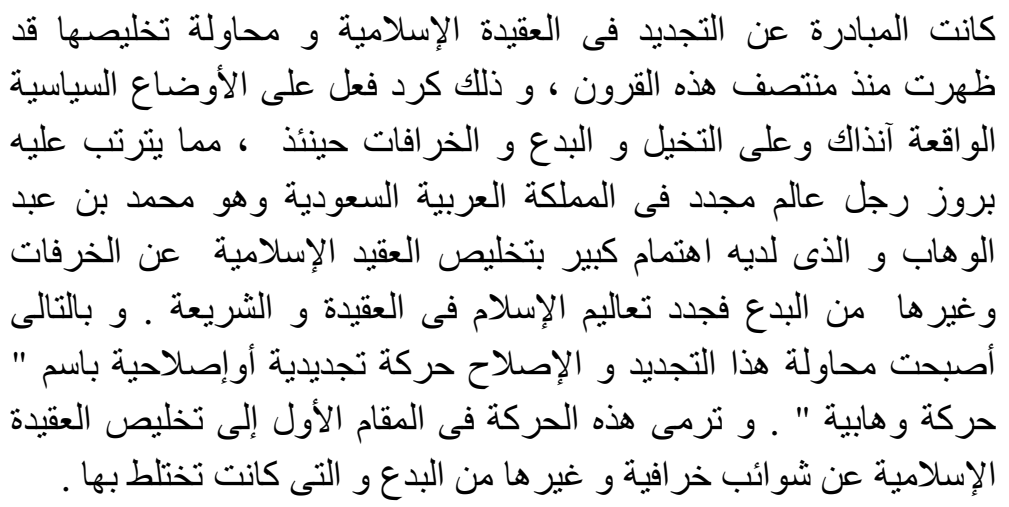

Kata Kunci: Muhammad ibn 'Abd al-Wahhâb, Gerakan Wahabi, pemurnian Islam, pembaruan Islam 


\section{PENDAHULUAN}

Di dunia Islam pada abad pertengahan (1250-1800 M) telah timbul ide-ide pembaruan dan upaya pemurnian akidah yang merupakan reaksi terhadap kondisi politik dan paham tauhid di kalangan umat Islam.

Di semenanjung Arabia, tampil ke atas pentas sejarah seorang tokoh terkemuka, Muhammad ibn 'Abd al-Wahhâb, yang memiliki perhatian yang amat besar terhadap masalah pemurnian akidah dan pembaruan dalam Islam.

Muhammad ibn 'Abd al-Wahhâb nama lengkapnya ialah Abû 'Abd Allâh Muhammad ibn 'Abd al-Wahhâb ibn Sulaymân Abû 'Alî b. Muhammad ibn Ahmad ibn Rasyîd al-Tamîmî (Al-Jundul, 1979:120). Ia dilahirkan di Nejd, suatu negeri yang terletak di jantung padang pasir yang masih murni keislamannya. Buku-buku sejarah pada umumnya mengungkapkan bahwa ia hidup antara tahun 1703 sampai tahun 1787 M.(Nasution, 1975:23).

Dalam watak, pengetahuan, dan pengalaman hidup Muhammad ibn 'Abd al-Wahhâb terhimpun potensi untuk mencetuskan ideidenya. Pemikiran yang dicetuskannya dalam memperbaiki kedudukan umat Islam timbul bukan reaksi terhadap suasana politik seperti yang terjadi di kerajaan Usmani dan kerajaan Mughal, tetapi sebagai reaksi terhadap paham tauhid di kalangan umat Islam pada waktu itu. Kemurnian paham tauhid mereka telah dirusak oleh ajaran-ajaran tarekat yang semenjak abad ke-13 tersebar luas di dunia Islam (Nasution, 1975:23).

Gagasan-gagasan Muhammad ibn 'Abd al-Wahhâb untuk memberantas bidah yang masuk ke dalam ajaran Islam akhirnya berkembang menjadi suatu gerakan yang disebut "Gerakan Wahabi”.

\section{SEKILAS TENTANG MUHAMMAD IBN 'ABD AI-WAHHÂB}

Muhammad ibn 'Abd Wahhâb dilahirkan di dusun Ujainah (Nejd), daerah Saudi Arabia sebelah timur (Hanafi, 1980:149). Dari ayahnya sebagai kadi, ia memperoleh pengetahuan di bidang fikih dan ilmu-ilmu keislaman lainnya. Kemudian ia merantau ke Hijaz. Di negeri ini Muhammad ibn 'Abd al-Wahhâb memperoleh pengetahuan 
agama dari ulama-ulama Mekkah dan Madinah. Setelah menyelesaikan pelajarannya di Madinah, ia merantau ke Basrah dan tinggal di kota ini selama empat tahun. Selanjutnya ia pindah ke Bagdad dan di sana ia memasuki hidup perkawinan dengan seorang wanita kaya. Lima tahun kemudian, setelah istrinya meninggal dunia, ia pindah ke Kurdistan, dan selanjutnya ke Hamdan dan Isfahan. Di kota Isfahan ia berhasil mempelajari filsafat dan tasawuf. Setelah bertahun-tahun merantau, akhirnya ia kembali ke tempat kelahirannya, Nejd (Nasution, 1975:23).

Setelah beberapa tahun dalam perlawatannya, ia kemudian kembali ke negeri kelahirannya. Selama beberapa bulan ia merenung dan mengadakan orientasi, ia kemudian mengajarkan pahampahamnya, terutama di bidang ketauhidan. Dari sinilah Muhammad ibn 'Abd al-Wahhâb memperoleh pengikut yang banyak, bahkan banyak di antaranya berasal dari luar Ujainah. Meskipun demikian, Muhammad ibn 'Abd al-Wahhâb memperoleh banyak tantangan, termasuk tantangan dari kalangan keluarganya sendiri (Hanafi, 1980:149).

Karena ajaran-ajarannya telah menimbulkan keributankeributan di negerinya, ia diusir oleh penguasa setempat. Akhirnya, ia bersama keluarganya berpindah ke Dar'iah, sebuah dusun tempat tinggal Muhammad ibn Sa'ûd (nenek Raja Faisal) yang telah menerima ajaran Wahabi, bahkan menjadi pelindung dan penyiarnya (Gibb \& Krames, 1953:618). Dari dukungan yang diberikan oleh Muhammad ibn Sa'ûd dan putranya 'Abd al-Azîz di Nejd, pahampaham Muhammad ibn 'Abd al-Wahhâb semakin tersiar dan gerakannya bertambah kuat. Sebagai seorang teoritis dan pemimpin, Muhammad ibn 'Abd al-Wahhâb secara aktif berusaha mewujudkan pemikirannya. Akhirnya, pada tahun 1773 M. ia bersama pengikutpengikutnya dapat menduduki Riyadh. Pada tahun 1787, Muhammad ibn 'Abd al-Wahhâb wafat, namun ajaran-ajarannya tetap hidup dengan mengambil bentuk aliran yang dikenal dengan nama Wahabi (Nasution, 1975:26), dan oleh Gibb disebutnya dengan "Gerakan Wahabi". "Gerakan Wahabi" bukan merupakan nama yang diberikan Muhammad ibn 'Abd al-Wahhâb, melainkan oleh golongan lain yang 
menjadi lawan-lawannya dan orang-orang Eropa. Para pengikut Muhammad ibn 'Abd al-Wahhâb sendiri menamakan dirinya sebagai kaum "Muhammadin" atau "Unitarian", yaitu orang-orang yang berusaha mengesakan Tuhan semurni-murninya (Gibb \& Kramers, 1953:618).

\section{GERAKAN WAHABI}

Hasil lawatan Muhammad ibn 'Abd al-Wahhâb ke beberapa wilayah kekuasaan Islam sebagaimana disebutkan sebelumnya, tampaknya merupakan indikator mengapa ia mendirikan suatu gerakan, yang selanjutnya dikenal dengan nama "Gerakan Wahabi". Di setiap negeri Islam yang dikunjungunya, ia melihat berbagai macam tradisi, kepercayaan, dan adat-istiadat yang dilakukan oleh masyarakat dalam bentuk ritual-keagamaan. Ia juga menyaksikan betapa besarnya pengaruh ahli-ahli tarekat di masa hidupnya sehingga kuburan-kuburan syaikh tarekat yang bertebaran di setiap kota, bahkan kampung-kampung, ramai dikunjungi oleh orang-orang yang ingin meminta berbagai macam pertolongan.

Karena pengaruh tarekat ini, permohonan dan doa tidak lagi langsung ditujukan kepada Tuhan, tetapi melalui syafaat para syaikh atau wali tarekat yang dipandang sebagai orang yang dapat mendekati Tuhan untuk memperoleh rahmat-Nya. Menurut keyakinan orangorang yang berziarah ke kuburan para syaikh dan wali tarekat, Tuhan tidak dapat didekati kecuali melalui perantara. Bagi mereka, sebagaimana kata Ahmad Amin (dalam Nasution, 1975:24), Tuhan menyerupai "Raja Dunia Zalim" yang untuk memperoleh belas kasihNya harus didekati melalui orang-orang besar dan penguasa yang ada di sekitarnya.

Muhammad ibn 'Abd al-Wahhâb melihat di beberapa negeri Islam yang dikunjunginya itu kehidupan Islam telah lenyap karena telah meninggalkan ritus yang tidak bernafaskan Islam, dan kemunduran yang merata (Stoddard, 1966:30). Kondisi umat yang telah rusak tauhidnya itulah yang tampaknya mendorong Muhammad ibn 'Abd al-Wahhâb untuk memperbaikinya lewat pemikiran dan ajaran-ajarannya. 
Muhammad ibn 'Abd al-Wahhâb dengan gerakannya untuk memurnikan ajaran Islam, khususnya dalam bidang tauhid sebagai ajaran pokok Islam, tidak ingin mengubah ajaran Islam dengan penafsiran baru terhadap wahyu, melainkan membawa misi memberantas unsur-unsur luar dari ajaran Islam, seperti bidah, khufarat, dan takhyul yang masuk ke dalam ajaran Islam. Dengan demikian, ia bermaksud mengajak umat Islam agar kembali kepada ajaran Islam yang murni (Antonius, 1939:22). Yang dimaksud dengan ajaran Islam yang murni itu ialah sebagaimana yang dianut dan dipraktekkan di zaman nabi, sahabat serta tabiin, yaitu sampai abad ke-3 Hijriah (Nasution, 1975:24).

Muhammad ibn 'Abd al-Wahhâb, tokoh dan pendiri Gerakan Wahabi yang sangat terkemuka di Saudi Arabia, merupakan tokoh Islam yang sangat terpengaruh oleh pengalaman keagamaan Ibnu Taimiyah pada khususnya, dan Mazhab Hanbali pada umumnya. (Amin, 1991:34). Oleh karena itu, tidak mengherankan jika dalam gerakannya, ia lebih banyak memfokuskan diri kepada pemurnian akidah.

Meskipun demikian, pemikiran pembaruan Muhammad ibn 'Abd al-Wahhâb banyak dipengaruhi oleh Ibnu Taimiyah tidak harus ditafsirkan bahwa Ibnu Taimiyah identik dengan kaum Wahabi sebab seperti yang dinyatakan oleh Muhammad Amin "walaupun dipengaruhi oleh pikiran-pikiran reformatif Ibnu Taimiyah, Gerakan Wahabi tidak sepenuhnya merupakan duplikat pikiran-pikiran Ibnu Taimiyah" (Donchue \& Esposito, 1984:x). Muhammad Amin (1991:34) menyatakan bahwa Gerakan Wahabi bukanlah gerakan yang taklid kepada Ibnu Taimiyah dan mengingkari pikiran-pikiran keagamaannya sendiri sebagaimana yang dituduhkan oleh sebagian orang, termasuk Husyn Hilmi Isikh dalam bukunya Advice for the Wahhabi.

Gerakan Wahabi dipelopori oleh Muhammad ibn 'Abd alWahhâb itu muncul tampaknya karena diguncang oleh kelemahankelemahan umat Islam di tempat ia dibesarkan dan tempat-tempat lain yang dikunjunginya, seperti pemujaan terhadap kuburan para syaikh atau wali dan lain-lain. Oleh karena itu, Muhammad ibn 'Abd alWahhâb sangat mengecam kepercayaan umat Islam terhadap kekuatan yang dimiliki oleh orang-orang yang dianggap keramat dalam rangka 
perbaikan moral dan spiritual. Di lain pihak, ia juga merasa kesal terhadap para ulama yang telah lama membiarkan praktek-praktek semacam itu. Dia juga mengecam orang-orang yang mau menerima secara taklid buta otoritas pihak-pihak tertentu dalam masalah keagamaan. Untuk itu, ia juga menyuruh umat Islam agar menyelaraskan nalar dan hati nurani mereka dengan Alquran dan sunah, dan bukan menyandarkan diri pada penafsiran-penafsiran tradisional (Mortimer, 1984:51). Oleh karena itu, Muhammad ibn 'Abd al-Wahhâb, terpaksa berhadapan dengan realitas kemapanan tradisional ulama-ulama yang mentolerir masuknya bidah ke dalam ajaran Islam. Ulama-ulama tersebut telah lama beradaptasi dengan masyarakat dan menjadikan bidah sebagai sandaran kekuatan moral. Dengan demikian, gerakan pemurnian akidah dan pembaruan Islam Muhammad ibn 'Abd al-Wahhâb tidak hanya diperhadapkan pada dilema ulama-ulama tersebut, tetapi lebih luas pada persoalan masal. Muhammad ibn 'Abd al-Wahhâb, sebagai tokoh yang sangat antusias mencetuskan gagasan-gagasannya, berupaya mengadakan pendekatan kepada kalangan atas, dan ternyata ia berhasil.

Muhammad ibn 'Abd al-Wahhâb memperoleh perlindungan dari pimpinan Nejd, Muhammad ibn Sa'ûd dan semangat pembaruannya menjadi kekuatan pendorong ekspansi politik keluarga Sa'ûd. Pada akhir abad ke-18, seluruh Nejd dapat ditaklukkannya, dan Irak pun diserbunya, yang berpuncak pada penjarahan Karbala. Kaum Wahabi memandang Karbala sebagai pusat takhayul Syi'ah, dan kota-kota suci Hijaz pun direbut dan dibersihkannya seluruh yang dianggapnya takhayul.

Al-Kindi (dalam Madjid, 1984:61) menyatakan bahwa dari waktu ke waktu senantiasa ada usaha pembaruan, penyegaran, atau pemurnian pemahaman umat terhadap agamanya, dan ini merupakan sesuatu yang telah menyatu dengan sistem Islam dalam sejarah. Nabi dalam sebuah hadis mengisyaratkan adanya hal itu. Dari sudut pandang ini, dapat dikatakan bahwa wajar saja bila pada abad ke-18, di Jazirah Arab, telah disaksikan usaha pembaruan yang militan,yang dilancarkan oleh Syaikh Muhammad ibn 'Abd al-Wahhâbyang melahirkan Gerakan Wahabi. Selain merupakan hampir satusatunya gerakan pembaruan keagamaan yang paling sukses secara politik karena telah bergabung dengan kekuatan Dinasti Sa'ûd, pembaruan di jazirah ini juga sangat menarik karena dilakukan tanpa 
sedikit pun persinggungan dengan kemodernan Barat (Madjid, 1984:61).

Dari penjelasan terdahulu terlihat bahwa Gerakan Wahabi, selain sebagai gerakan pemurnian disebut pula dengan gerakan pembaruan.

\section{AJARAN MUHAMMAD IBN ‘ABD AL-WAHHÂB}

Bila dilihat dari karya ilmiah yang ditulis, Muhammad ibn 'Abd al-Wahhâb dapat dikategorikan sebagai sosok ulama yang produktif. Karya-karya ilmiahnya mencapai puluhan jumlahnya. Antara lain Tafsîr Sûrat al-Fâtihah, Mukhtasâr Sahîh al-Bukhârî, Mukhtasâr Sîrat al-Nabawiyyah, Kitâb al-Tauhîd, Usûl al-Imân, Kitâb al-Kabâ'ir, Kasyi al-Subyât, Thalathal al-Usûl, Adab al-Masyî̀ ilâ al-Salâh, dan al-Hadîth al-Fitn (Al-Jundul, 1979:13). Tema dari karya-karya ilmiah Muhammad ibn 'Abd al-Wahhâb ini tampaknya terfokus pada misi pemurnian tauhid.

Ajaran tauhid memang merupakan ajaran yang paling dasar dalam Islam. Oleh karena itu, tidak mengherankan jika Muhammad ibn 'Abd al-Wahhâb memusatkan perhatian pada masalah ini. Ia berpendapat bahwa (1) yang boleh dan harus disembah hanyalah Tuhan, dan orang-orang yang menyembah selain Tuhan telah menjadi musyrik, dan boleh dibunuh; (2) kebanyakan orang Islam bukan lagi penganut paham tauhid yang sebenarnya karena mereka meminta pertolongan bukan lagi kepada Tuhan, tetapi kepada para syaikh atau wali dan dari kekuatan gaib. Orang Islam demikian juga telah menjadi musyrik; (3) menyebut nama nabi, syaikh atau malaikat sebagai perantara dalam doa juga merupakan syirik; (4) meminta syafaat selain kepada Tuhan adalah juga syirik; (5) bernazar kepada selain Tuhan juga syirik; (6) memperoleh pengetahuan selain dari Alquran, hadis, dan kias (analogi) merupakan kekufuran;(7) tidak percaya kepada kada dan kadar Tuhan juga merupakan kekufuran; dan (8) penafsiran Alquran dengan takwil (interpretasi bebas) adalah kufur (Nasution, 1975:25).

Bila diamati seluruh butir ajaran tersebut di atas, pada prinsipnya butir-butir ajaran tersebut bertemakan pemurnian tauhid (akidah). Harun Nasution lebih lanjut menjelaskan bahwa semua poin di atas oleh Muhammad ibn 'Abd al-Wahhâb) diannggapnya bidah dan bidah adalah kesesatan. Oleh karena itu, untuk melepaskan umat 
Islam dari praktek-praktek bidah, merela harus kembali kepada Islam asli (Nasution, 1975:25). Dengan demikian, delapan butir ajaran di atas dapat dijadikan acuan dalam melihat gerakan pemurnian dalam bidang akidah.

Untuk mengembalikan kemurnian tauhid, kuburan-kuburan yang banyak dikunjungi dengan tujuan mencari syafaat, yang dapat membawa kepada paham syirik, gerakan ini berusaha menghapusnya (Nasution, 1975:26). Tarekat-tarekat sufi yang mempunyai pengaruh negatif terhadap umat Islam ditentangnya karena tarekat adalah bidah (sesuatu yang berasal bukan dari agama Islam, tetapi datang dari luar). Tantangan terhadap tarekat dimulai oleh Muhammad ibn 'Abd alWahhâb (1703-1787) di Arabia, dan kemudian diteruskan oleh tokohtokoh pembaruan periode baru sehingga ide perubahan mulai masuk ke dalam masyarakat Islam (Nasution, 1995:168).

Harun Nasution (1975:26) mengemukakan tiga pokok pikiran Muhammad ibn 'Abd al-Wahhâb yang mempunyai pengaruh terhadap perkembangan pemikiran pembaruan abad ke-19, yaitu (1) hanya Alquran dan hadislah yang merupakan sumber asli ajaran-ajaran Islam. Pendapat ulama tidak merupakan sumber; (2) taklid kepada ulama tidak dibenarkan; dan (3) pintu ijtihad tetap terbuka.

Di antara ketiga pokok-pokok pikiran di atas, mungkin hanya poin terakhir satu-satunya yang dapat dijadikan dasar untuk menyatakan Gerakan Wahabi sebagai Gerakan Pembaruan. Adapun poin pertama dan kedua tetap merupakan dasar yang memperkuat untuk menyatakan Gerakan Wahabi adalah Gerakan Pemurnian dalam Islam, khususnya dalam bidang akidah (tauhid). Namun demikian, tidak keliru jika dikatakan bahwa Gerakan Pembaruan kaum Wahabi memberi dampak yang sangat positif bagi dunia Islam.

Setelah berdiri kokoh di Nejd, Gerakan Wahabi segera tersebar ke negara-negara lain, seperti Indi, Sudan, Libia, dan Indonesia. Di India, ajaran Wahabi dibawa oleh Sayyid Ahmad, yaitu setelah ia menunaikan ibadah haji pada tahun 1822 dan 1823. Di India, ajaran Wahabi mendapat pengikut-pengikut yang kemudian siap melakukan perang melawan kaum kafir dan non-Muslim. Di Indonesia, ajaran Wahabi masuk melalui kaum Paderi di Minangkabau yang dimotori oleh tiga orang ulama Minangkabau, yaitu H. Sumanik dari Lunak Tanah Datar, H. Piobang dari Lunak 50 Kota, dan H. Miskin dari Lunak Agam (Atjeh, 1970:87). 
Dari informasi sejarah ini, dapat dikemukakan bahwa telah terjadi pergeseran sasaran yang ingin dicapai oleh gerakan ini. Semula gerakan ini berusaha memurnikan tauhid, tetapi ternyata dalam perkembangan berikutnya telah jauh memasuki bidang politik. Agaknya keadaanlah yang memaksa gerakan ini berbuat demikian karena setiap agama yang dianut oleh suatu umat tidak terlepas sama sekali dari kondisi sosial masyarakat.

\section{PENUTUP}

Dari uraian di atas, dapat dikemukakan bahwa sebagai pendiri Gerakan Wahabi, Muhammad ibn 'Abd al-Wahhâb memiliki perhatian yang amat besar terhadap masalah pemurnian akidah dan pembaruan dalam Islam. Karena keinginannya untuk memperbaiki keadaan umat Islam, dicanangkannyalah upaya pemberantasan takhyul, bidah dan khurafat).

Gerakan pembaruan Muhammad ibn 'Abd al-Wahhâb yang bersumber dari ide dasar bahwa pintu ijtihad tetap terbuka, memberi dampak positif terhadap dinamika pembaruan pemikiran Islam pada abad ke-19.

Gerakan pemurnian dan pembaruan Wahabi yang kadangkadang menempuh cara-cara yang kaku dan tak kenal kompromi, kadang-kadang pula diwarnai oleh suasana konflik dengan kelompok lain. Oleh karena itu, Gerakan Wahabi sering dituduh sebagai kelompok pembangkang oleh pihak-pihak yang tidak sepaham dengan ajaran-ajaran gerakan pemurnian dan pembaruan ini.

\section{DAFTAR PUSTAKA}

Antonius, George. 1939. The Arabs Awakening. New York: Gordon Press. Amin, Muhammad. 1991. Ijtihad Ibnu Taimiyah. Jakarta: INIS.

Atjeh, Abu Bakar. 1970. Salaf. Jakarta: Permata.

Donchue, John J. \& Espito, John L. 1984. Islam in Transition Muslim Perspective. Terjemahan oleh Machnun Husein. Jakarta: Rajawali.

Gibb, H.A.R. \& Kramers, J.H. (Eds.). 1953. Shorter Encyclopedia of Islam. Leiden: B.J. Brill.

Hanafi, A. 1980. Teologi Islam. Jakarta: Pustaka Al-Husna.

al-Jundul, Sa'îd. 1979. Al-Durr al-Naqdî 'alâ Kitâb al-Tauhidî al-Syaikh alIslâm Muhammad ibn 'Abd al-Wahhâb. Riyadh: Al-Mustauda' al'Amm 
Jurnal Hunafa,Vol. 5, No. 3, Desember 2008:319-328

Madjid, Nurcholis. 1984. Khazanah Intelektual Islam. Jakarta: Bulan Bintang.

Nasution, Harun. 1975. Pembaharuan dalam Islam. Jakarta: Bulan Bulan Bintang.

1995. Islam Rasional: Gerakan dan Pemikiran. Bandung: Mizan.

Mortimer, Edward. 1984. The Politics of Islam. Terjemahan oleh Enna Hadi \& Rahmani Astuti. Bandung: Mizan.

Stoddard, Lothrop. 1966. Dunia Baru Islam. Terjemahan oleh Panitia Penerbit: Jakarta: t.p. 